\title{
A Educação Aberta e a Distância e a Formação de Mediadores de Leitura através das Tecnologias de Informação e de Comunicação
}

\author{
Eliane Lourdes da Silva Moro ${ }^{1}$, Lizandra Brasil Estabel ${ }^{2}$ \\ 1 Departamento de Ciências da Informação da Faculdade de Biblioteconomia e \\ Comunicação da Universidade Federal do Rio Grande do Sul (DCI/FABICO/UFRGS) \\ 2 Instituto Federal do Rio Grande do Sul (IFRS)- Câmpus Porto Alegre \\ eliane_moro@yahoo.com.br, lizandra.estabel@poa.ifrs.edu.br
}

\begin{abstract}
The continuous training of teachers is crucial for teachers to make use of Information Technology and Communication (ICT) and Virtual Learning Environments (VLEs) in the educational setting. This article presents an experiment conducted in the Extension Course "Mediators in Reading Bibliodiversidade", conducted by the Research Group LEIA UFRGS, IFRS, recorded in Cnpq, in partnership with the SEAD / UFRGS, MEC and UAB from 2010 to 2011, in ODL mode, computer mediated, in order to update and qualification of teachers working in the public school system of Rio Grande do Sul, in order to qualify teachers to mediate the reading.
\end{abstract}

Resumo. A contínua formação de professores é fundamental para que os professores façam uso das Tecnologias de Informação e de Comunicação (TICs) e de Ambientes Virtuais de Aprendizagem (AVAs) no cenário educacional. Este artigo apresenta uma experiência realizada no Curso de Extensão "Mediadores de Leitura na Bibliodiversidade", realizado pelo Grupo de Pesquisa LEIA da UFRGS, IFRS, registrado no Cnpq, em parceria com a SEAD/UFRGS, MEC e UAB, de 2010 a 2011, na modalidade EAD, mediada por computador, visando a atualização $e$ a qualificação de professores que atuam no sistema de ensino público do Rio Grande do Sul, a fim de qualificar os professores para a mediação da leitura.

\section{Introdução}

A Educação Aberta e a Distância (EAD) se caracteriza como uma modalidade educacional na qual a mediação didático-pedagógica nos processos de ensino e aprendizagem se efetiva com o uso das Tecnologias de Informação e de Comunicação (TICs), com a participação de professores e alunos que realizam atividades de ensino e de aprendizagem em lugares e tempos diversos, conforme determina o Decreto $\mathrm{N}^{\mathrm{o}} 5.622$ de 19 de dezembro de 2005 que regulamenta o Art. $N^{\circ} 80$ da Lei de Diretrizes e Bases da Educação Nacional (LDBEN) e define, no Art. $1^{\circ}$, a Educação a Distância. No Art. $2^{\circ}$ determina que a EAD pode ser ofertada nos seguintes níveis e modalidades educacionais: Educação Básica; Educação de Jovens e Adultos; Educação Especial; Educação Profissional (níveis médio e superior) e Educação Superior, abrangendo os cursos e programas: Seqüenciais, de Graduação, de Especialização, de Mestrado e de Doutorado.

Ramal (2001, p.15) afirma que a EAD "processa-se em um contexto de novos sujeitos, resultado das mudanças nas relações entre trabalho, cidadania $\mathrm{e}$ aprendizagem". Por outro lado, a informática tem o poder de transformar o conhecimento em algo que não se caracteriza como material, flexível, fluído e indefinido, provocando dessa forma, rupturas: a interatividade, a manipulação de dados, a correlação dos saberes através da rede, o apagamento das fronteiras rígidas entre 
texto-margens e autores-leitores. Para a autora, os suportes digitais e os hipertextos são, a partir de agora, "as tecnologias intelectuais de que a humanidade passará a se valer para aprender, interpretar a realidade e transformá-la". Portanto, a EAD terá sua legitimidade conquistada através de estratégias inteligentes, que entre outras dinâmicas, compreenderão a realização de testes "on-line", o acompanhamento personalizado, destacando-se o atendimento às diferenças individuais dos alunos e novos conceitos de avaliação.

Assim, a EAD envolve diversos componentes, como ensino, aprendizagem, informação, comunicação, planejamento, gerenciamento, entre outros. Se considerarmos os dias atuais, reveste-se de grande importância a constante atualização dos profissionais do cenário educacional.

Os conhecimentos e habilidades empregados em um campo profissional são cada vez menos estáveis; em intervalos de tempo cada vez mais curtos, transformando-se e, até mesmo, tornando-se obsoletos. As novas formas de trabalho, as crescentes demandas resultantes dos avanços que a ciência introduz nas áreas técnicas e tecnológicas, nos sistemas de comunicação, de transporte, e mesmo nas formas de relação, organização e lazer requerem um maior acesso a novas informações e um contínuo desenvolvimento de novas facilidades para a adaptação e assimilação destas mudanças. (PEDROSA, 2003, p.70).

A contínua formação de professores é fundamental para a modernização do ensino e a utilização das TICs e de Ambientes Virtuais de Aprendizagem (AVAs) no cenário educacional. Segundo Pedrosa (2003, p.72) a formação é entendida tanto como "uma ação na busca do conhecimento formal, como numa tomada de consciência de sua práxis, da própria atividade pedagógica". Este processo de continuo aperfeiçoamento e atualização propicia segurança para os profissionais que atuam na educação e permitilhes visualizar novas perspectivas e desafios na sua atuação.

Diante do exposto, o Grupo de Pesquisa LEIA (Leitura, Informação e Acessibilidade) da UFRGS e do IFRS, registrado no Cnpq, realizou em 2010 e 2011 o Curso de Extensão "Mediadores de Leitura na Bibliodiversidade" em parceria com a Secretaria de Educação a Distância (SEAD/UFRGS), Ministério da Educação (MEC) e Universidade Aberta do Brasil (UAB), na modalidade EAD, mediada por computador, a formação de 630 mediadores de leitura que atuam em escolas públicas (estaduais e municipais) do Estado visando a atualização e a qualificação de professores que do sistema de ensino público estadual e municipal do Rio Grande do Sul, a fim de qualificar os professores para a mediação da leitura através do uso das TICs em um AVA.

\section{Professor como Mediador e a Educação Aberta e a Distância}

$\mathrm{O}$ termo mediador deriva do latim mediatore e significa "aquele que medeia ou intervém". Em se tratando de leitura, pode-se considerar que o mediador do ato de ler é o indivíduo que aproxima o leitor da narrativa e que facilita esta relação. $\mathrm{O}$ papel do mediador é de grande significado no processo de inclusão social, de acesso à informação, de uso das TICs e do exercício da cidadania, no que se refere à formação do leitor e ao incentivo à leitura.

A leitura se reveste de grande importância e significado em todo o desenvolvimento na vida das pessoas, compreendida como práticas e representações sociais desde o nascimento até a morte, permanente no processo do desenvolvimento humano, em uma interação com o mundo e com o outro. 
Em uma sociedade que não lê, a conquista da leitura é o primeiro passo para a formação dos valores da sociedade, propiciando a participação social, compreensão do homem pelo homem, nível cultural, forma de lazer, formação e exercício da cidadania, entre outros. A formação do leitor envolve os aspectos político, psicológico e metodológico através das ações de leitura, considerada como um processo constante de esforços conscientes da área educacional. (MORO; ESTABEL, 2011, p.78).

Por isso, afirmam que "o processo da leitura na escola e na biblioteca deveria ser iniciado na família, sem que esta postergue para a escola o papel da formação do leitor e do incentivo à leitura" (MORO; ESTABEL, 2011, p.77). Cada fase da vida deve ser vivenciada com a leitura estimulada e propiciada pela família e pela escola. Ninguém nasce sabendo ler, aprende-se a ler à medida que se vive, como Freire (1982) nos reporta que a leitura do mundo precede a leitura da palavra e se apropriar da leitura, da escrita, se alfabetizar é, antes de mais nada, aprender a ler o mundo, compreender o seu contexto, não numa manipulação mecânica de palavras, mas numa relação dinâmica que vincula linguagem, realidade e vida.

O Curso de Mediadores de Leitura na Bibliodiversidade tem como foco a formação de leitores e o incentivo à leitura em todas as instâncias sociais, principalmente na instituição escolar com atividades e dinâmicas de leituras nas salas de aula e bibliotecas escolares entre outros espaços comunitários, envolvendo os escolarizados, os neoleitores e as pessoas da comunidade em todos os níveis de leitura.

No cenário da sala de aula ou no espaço virtual, os principais protagonistas do ato de ensinar e aprender são o professor e o aluno. Muitos outros coadjuvantes fazem parte do cenário, contribuindo para que o processo de ensino e de aprendizagem se realize com sucesso, como as direções e/ou coordenações, os supervisores pedagógicos, os orientadores educacionais, os bibliotecários, os pais, a família, os dirigentes do sistema educacional, os governantes, os legisladores. Cada um dos coadjuvantes tem o seu papel: colaborar para que os professores e alunos transformem suas vidas em processos permanentes de aprendizagem. O papel fundamental do professor é o de mediador, seja presencialmente, seja a distância, a fim de possibilitar que o aluno possa aprender, exercer a cidadania e se tornar um ser humano feliz na sociedade em que vive.

A educação está em constante evolução, havendo necessidade de atualização do professor, da mudança do seu perfil e do seu fazer, resultando numa profunda mudança comportamental e exercendo um novo papel no cenário social.

$\mathrm{Na}$ escola tradicional, a função do professor era somente ensinar, transmitir conhecimento e acumular o aluno de informações. O professor era somente um emissor, não compromissado com a mensagem enviada e reelaborada, mas sim com a mensagem enviada e simplesmente decodificada. Hoje, o professor como mediador, interage com o aluno, ambos são emissores e receptores, expressores e perceptores, estabelecendo uma relação de troca, de cooperação, de construção em comum.

O professor avalia seu aluno integralmente, equilibrando o quantitativo com o qualitativo, nos aspectos afetivos, cognitivos e psicomotores. O professor/mediador na "Era do Conhecimento" deveria apresentar o seguinte perfil comportamental: Ensinar o aluno a aprender a aprender; Perder o medo do computador; Perder a vergonha de dizer que não sabe; Inverter a lógica da escola tradicional e trabalhar a partir das questões dos alunos; Garantir o acesso do aluno à informação; Mostrar que a tecnologia está a serviço do homem, deve ser usada para a libertação e precisa ser operada com ética; Orientar o aluno na busca de conhecimento no mundo de informações aberto pela Internet; 
Compreender que o conhecimento é dinâmico e está em constante expansão; Saber que só se ensina aprendendo; Ensinar ao aluno que há diferentes caminhos e fórmulas para o mesmo problema, que é preciso testar soluções, cruzar conhecimentos, trocar experiências, expandir; Auxiliar o aluno a desenvolver a capacidade crítica, a distinguir a falsa informação da verdadeira; Estimular a curiosidade, a estranheza e o espanto e direcioná-los para busca do conhecimento; Valorizar idéias, sensibilidades e capacidades de criação; Valorizar, respeitar e dar espaço para as diferenças; Saber ser o orientador da busca pelos caminhos e possibilidades de um mundo onde nada mais é estático, definitivo ou seguro.

O papel desse professor é compreender que o conhecimento não é padronizado e estático e que seus alunos deverão ser preparados com discernimento e independência diante de um mundo que muda velozmente. O professor deve procurar descobrir o seu lugar de verdadeiro educador e que compreender a escola como um espaço de inclusão, um lugar para todos. Deve estar constantemente atualizado em função da velocidade das mudanças e de novos paradigmas, pois o que é novo hoje amanhã poderá estar superado.

No ambiente virtual, frente às TICs, o professor deve assumir a postura de educador e o aluno de aprendiz. O educador e o aprendiz também devem assumir novas posturas com relação às tecnologias informatizadas.

No contexto da Sociedade da Informação, ocorreu a popularização das tecnologias e este fenômeno possibilitou que o aluno tivesse acesso à informação e à leitura com mais facilidade, mas ter acesso não significa que estas ferramentas são utilizadas com qualidade. Em geral, a utilização das tecnologias está muito mais focada no processo de comunicação, através das redes sociais de relacionamento, e/ou para as estratégias de busca, com fins acadêmicos, restrita ao uso de buscadores como o Google, sem uma filtragem e seleção à informação de qualidade e credibilidade.

Vive-se hoje a Sociedade do Conhecimento (e da Aprendizagem) e faz-se necessário que o professor mediador, saiba utilizar as tecnologias para que possa orientar o aluno na busca e no acesso às fontes de informação para que este possa distinguir a informação com qualidade, também no uso destas ferramentas para que possa compreender melhor determinado conteúdo, desenvolver novas habilidades e competências que propiciem o seu desenvolvimento e o aprendizado.

O aprendiz do século XXI (AASL, 2011) deverá ter competência para: Investigar, pensar criticamente e adquirir conhecimento; Tirar conclusões, tomar decisões embasadas, aplicar o conhecimento adquirido a novas situações e gerar novos conhecimentos; Compartilhar conhecimento e atuar de modo ético e produtivo como membro de uma sociedade democrática; Buscar aprimoramento pessoal e estético.

Estas competências devem ser desenvolvidas na relação entre professores e alunos, em um processo de aprendizado e construção conjunta, mediado pelo uso das TICs e dos AVAs, através da EAD.

\section{Curso Mediadores de Leitura na Bibliodiversidade}

No cenário das escolas, embora um significativo número disponham das ferramentas tecnológicas para o ensino e a aprendizagem, preocupa ainda, a falta de uma "ação pedagógica digital", que propicie a articulação dos atores (alunos e professores) na comunidade escolar, através do uso de informações que visam a construção de cidadania e integração social. Um dos fatores que os atores deste cenário devem levar em consideração é o papel que as TICs exercem como mediadoras do processo de 
ensino e de aprendizagem, através do AVA, na estratégia educativa em que dois ou mais sujeitos constroem seu conhecimento através da discussão, da reflexão e da tomada de decisões. Os efeitos do uso da informação compartilhada entre os educadores e os alunos, pode encaminhar para uma rede integrada de comunicação, permitindo o estabelecimento de novas relações entre os mesmos (inter-relação de pessoas) e destes com a comunidade escolar.

Diante da realidade apresentada, a Universidade Federal do Rio Grande do Sul (UFRGS) através do Grupo de Pesquisa (Leitura, Informação e Acessibilidade), e da competência para ofertar cursos de extensão, formação, aperfeiçoamento e pósgraduação (lato sensu e stricto sensu), planejou e realizou o Curso de Extensão "Mediadores de Leitura na Bibliodiversidade", no período de 2010 a 2011, em parceria com a SEAD/UFRGS, o MEC e a UAB, na modalidade EAD, mediada por computador, visando a atualização e a qualificação de professores que atuam no sistema de ensino público estadual e municipal do Rio Grande do Sul.

A proposta do Curso teve como objetivos gerais: fomentar a adesão das propostas de leitura e a inserção dos temas da diversidade e da inclusão no processo da mediação de leitura e da formação continuada de mediadores na educação básica brasileira da rede pública e ampliar a competência leitora, o gosto e o prazer pela leitura, mediante apropriação da leitura literária como pratica cognitiva e social no enfoque leitor forma leitor. Os objetivos específicos são: Oportunizar a formação continuada de educadores, bibliotecários e gestores educacionais da rede pública de educação básica como mediadores de leitura; Propiciar aos participantes condições de desenvolver competências para a fruição de obras por meio da leitura e do compartilhamento de experiências entre os pares; Promover a reflexão e o debate sobre os aspectos teóricos de leitura e da mediação da leitura abrangendo os processos psicológico, metodológico e político de leitura; Oferecer subsídios para o planejamento e a implementação de programas de leitura para leitores reais e potenciais da comunidade escolar; Identificar modalidades de práticas leitoras e fontes literárias que possam conduzir o leitor a fruir diferentes linguagens em diferentes ambientes; Estudar a construção estética dos textos tendo em vista o seu caráter literário, sua tipologia para uso pedagógico e de lazer; Promover a interação, a mediação, o compartilhamento entre os participantes e a equipe executora através do acesso e do uso das TICs; Acompanhar, assessorar e avaliar o processo de aprendizagem dos participantes.

A coordenação do Curso, inicialmente teve a preocupação de pensar em uma identidade visual do Curso Mediadores de Leitura na Bibliodiversidade a fim de identificar e padronizar todo o material produzido, no suporte bibliográfico e eletrônico. Por isso foi criado o logo (Figura 1) e a página virtual no seguinte endereço: http://www.ufrgs.br/mediadoresdeleitura/

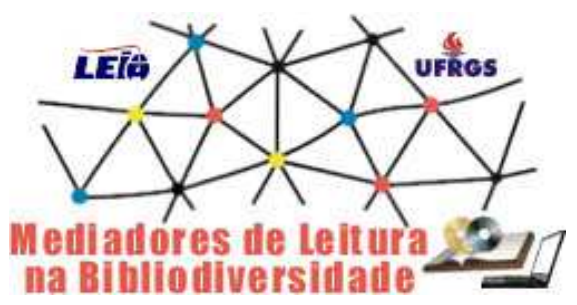

Figura 1. Logotipo do Curso

O logo apresenta a imagem de uma teia formada por diversos nós. Estes nós representam cada um dos pólos, os participantes do Curso (professores), a comunidade escolar onde atuam e a equipe de trabalho do Curso (coordenação, professores e tutores) 
e sua importância para que se estabeleça uma rede de construção de saberes, de troca, de mediação e de interação para a promoção da leitura e formação de professores. Ainda são representados os suportes de informação e de leitura através da imagem de mídias digitais, do livro e do computador. A discussão e aprovação do logo, desde a sua formatação, simbologia e cores teve a participação de toda a equipe de trabalho do Curso Mediadores de Leitura na Bibliodiversidade: coordenação, professores e tutores.

O Curso de Extensão de Mediadores de Leitura na Bibliodiversidade dos Pólos da UAB I do Estado do Rio Grande do Sul, nas modalidades EAD (80h) e presencial (10h), foi estruturado em 5 (cinco) Módulos, totalizando 90 horas. Nos 3 (três) meses anteriores ao início do mesmo, foram produzidos materiais e objetos de aprendizagem (OA) em diferentes mídias impressas, eletrônicas e digitais. Como produto final do Curso foi publicado o livro "Mediadores de Leitura na Bibliodiversidade" patrocinado pelo MEC, UAB e CAPES.

Este Curso atendeu 18 (dezoito) dos 32 (trinta e dois) que constituem os Pólos da UAB I, no Rio Grande do Sul (Figura 2), e foram oferecidas 35 (trinta e cinco) vagas por Pólo, totalizando 630 vagas. Em razão do número de Pólos e, principalmente do número dos participantes, a serem atendidos por Pólo, 35 (trinta e cinco) o Curso foi oferecido em duas etapas:

Primeira Etapa: Grupo A: 09 (nove) Pólos: Agudo, Faxinal do Soturno, Herval, Hulha Negra, Mostardas, Restinga Sêca, Santana da Boa Vista, Santana do Livramento, Sobradinho.

Segunda etapa: Grupo B: 09 (nove) Pólos: Camargo, Cerro Largo, Constantina, Cruz Alta, Jacuizinho, Seberí, Tapejara, Tio Hugo, Três de Maio.

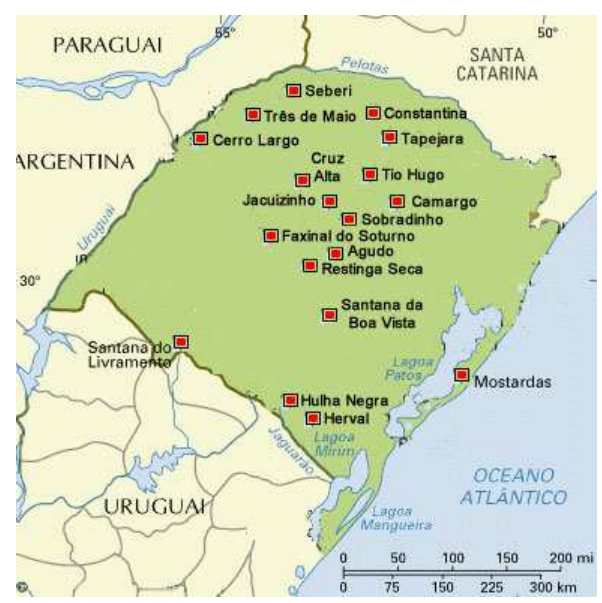

Figura 2: Pólos da UAB 1 atendidos no Curso

O público beneficiário se constituiu de professores e gestores da educação básica do sistema de ensino público estadual e municipal, estes últimos, em sua maioria. Um dos motivos principais da participação majoritária de professores foi a exigência da SECADI / MEC da inscrição do participante no Sistema Universidade Aberta do Brasil (SISUAB) mediante a sua credencial de professor do ensino público.

A equipe do Curso foi formada por 1 (um) Coordenador do Curso, 1(um) Coordenador de Tutoria, 7 (sete) Professores Conteudistas, 9 (nove) Professores Ministrantes do Curso, uma equipe de 18 (dezoito) Tutores em EAD e Presenciais, 1(um) revisor, 1(um) Assistente Financeiro, 1(um) Webdesigner e 1(uma) Secretária . 
A metodologia de ensino, na modalidade EAD mediada por computador, possibilitou o desenvolvimento de estratégias de aprendizagem e a publicação na plataforma do curso, AVA Moodle, das atividades previstas para cada componente da base curricular, por meio de uma seqüência de fases programadas nos seguintes módulos:

a) Módulo I: EAD e Ferramenta Moodle (10h)

b) Módulo II: A Construção do Eu Leitor/Mediador (15h)

c) Módulo III: Imersão Cultural (25h)

d) Módulo IV: Gêneros textuais (20h) Modalidade: EAD mediado por computador

e) Módulo V: Itinerário e experimentação de práticas de leituras (20h)

f) Seminário de Avaliação (presencial), realizado no Pólo (10h), e Apresentação de um Projeto de Ação para ser aplicado no Pólo do participante do Curso.

A modalidade EAD, através da utilização do AVA MOODLE, propiciou que profissionais residentes em 18 municípios do Estado do Rio Grande do Sul realizassem as atividades síncronas e assíncronas, sem a necessidade do afastamento, em exercício, nas funções profissionais.

O uso de AVAs podem transpor e potencializar as fronteiras existentes na utilização de recursos didáticos nos meios tradicionais de ensino, uma vez que produzem a rica experiência da intertextualidade entre o material utilizado, ou seja, recursos de texto e hipertexto, recursos visuais ou sonoros dialogam entre si, oferecendo ao participantes a possibilidade real de construir o conhecimento de modo interativo e colaborativo. Os AVAs propiciam o acesso e o uso de TICs e espaços de informação, de aprendizagem, de interação, de comunicação, de compartilhamento entre os sujeitos que favorecem o desenvolvimento e a vivência da inclusão social, digital e informacional e o exercício da cidadania e funcionam como facilitadores na realização de cursos de formação e de educação continuada a profissionais que atuam em escolas.

\section{O Professor como Mediador de Leitura no uso das Tecnologias de Informação e de Comunicação}

O uso das TICs e a possibilidade de acesso à Internet permite que os professores possam fazer uso destes recursos para a sua formação, mediação e interação com os seus alunos. A Educação a Distância é uma das possibilidades de construção de conhecimento, onde os protagonistas (professores e alunos) passam a ser agentes ativos do seu processo de aprendizagem. Através da interação com o outro, com o grupo, este sujeito sente-se parte de uma rede adquirindo autonomia e melhorando a sua auto-estima, sentindo-se capaz. Neste novo cenário educacional, acredita-se que cada ator deve se responsabilizar pelo seu aprendizado e pelo do grupo. Professores e alunos são responsáveis por este processo. Ações de cooperação permitirão que limitações impostas pelas tecnologias sejam superadas através do compartilhamento das dificuldades buscando soluções para os problemas apresentados. O professor, ao fazer parte deste cenário, sentir-se-á estimulado a fazer uso das tecnologias com seus alunos, sendo um agente de inclusão social e digital e mediador de leitura.

Lopes (2005, p.49) referindo-se aos novos ambientes de aprendizagem afirma que estes exigem do educador-pesquisador a "competência de saber trocar saberes, habilidades para construir e reconstruir com seus alunos conhecimentos significativos, 
para conhecer o erro como fator de construção e saber lidar com as incertezas, as transitoriedades, os problemas".

O professor deve encantar os seus alunos propiciando o diálogo, a interação, a criatividade, o compartilhamento. $\mathrm{O}$ ambiente digital deve ser agradável, prazeroso possibilitando que o aluno sinta-se capaz de produzir, de criar, de construir. A conjugação destes verbos possibilita que o sujeito adquira autonomia e que professores e alunos aprendam conjuntamente e façam novas descobertas.

O uso das TICs na Educação não quer dizer que a aula tornar-se-á mais atrativa ou mais interessante. As ferramentas são muitas e as possibilidades de uso destas são as mais variadas. No entanto, cabe ao professor e ao aluno assumir uma postura de cooperação. Muitos são os obstáculos a serem transpostos como: a falta de equipamentos adequados e de condições, dificuldades como, demora na transferência de dados, quedas de luz e de conexão, impaciência, frustração, enfim, problemas que deverão ser superados pelo grupo e em ação conjunta, professor e aluno e alunos entre alunos.

No AVA o papel do educador é o do mediador, propiciando o exercício da colaboração e da cooperação das atividades realizadas, com a participação ativa das situações de aprendizagem propostas, transformando os espaços de sala de aula em ambientes efetivos de aprendizagem. Nesse ambiente os alunos tornam-se o centro do processo de ensino e de aprendizagem, tornando-se responsáveis pela sua aprendizagem e co-responsáveis pela aprendizagem do grupo do qual fazem parte.

As ferramentas utilizadas no AVA devem ser selecionadas pelo educador, tendo em vista o perfil, as características e as necessidades do grupo, para o bom desempenho das atividades síncronas (que exigem a conexão simultânea dos participantes) e assíncronas (que permitem a interação dos sujeitos independente de tempo e espaço) que serão desenvolvidas, bem como a preocupação para que as mesmas propiciem um ambiente de interação e de acesso à informação.

Para que a aprendizagem se realize, é necessário que haja interação entre os sujeitos, pois segundo Rego (1995, p.71) "o desenvolvimento pleno do ser humano depende do aprendizado que realiza num determinado grupo cultural, a partir da interação com outros indivíduos da sua espécie". A aprendizagem colaborativa apoiada por computador deve ser uma estratégia educativa que possibilite a discussão, o diálogo, a reflexão, a tomada de decisão, tendo como instrumento mediador o computador. Para que este processo ocorra, professores e alunos devem estar dispostos a colaborarem e construírem conjuntamente.

Para que o grupo se fortaleça faz-se necessário que tenham objetivos comuns, todos devem contribuir uns com os outros. O grupo deve sempre retomar as atividades, fazendo uma avaliação do processo para que sejam reformulados os pontos que devem ser aprimorados e propiciar uma reflexão diante do processo de construção colaborativa.

No entanto, este processo somente ocorrerá se forem utilizadas ferramentas que possibilitem esta colaboração.

Diante do exposto, foi proposta a criação de blogs, em grupos, para que os professores pudessem

expressarem a si mesmos, trocar conhecimento entre si, e abordar, de modo criativo, textos, imagens e outros assuntos relacionados à leitura, trazendo para este meio o seu aluno da escola e, desejavelmente, pessoas ligadas a esse. Em outras palavras, pretendia-se a extensão, do curso, de um ambiente virtual de aprendizagem para um ambiente virtual de compartilhamento e de domínio público, possibilitador do surgimento de uma grande cadeia inclusiva (ULLRICH, 2012, p.169). 
A criação deste blogs, representando dezoito pólos da UAB do Rio Grande do Sul, estabeleceu uma rede de interação, de trocas, de compartilhamento e de difusão da leitura e da cultura local. Histórias foram compartilhadas, projetos colocados em práticas, poesias foram criadas, práticas leitoras foram estabelecidas. Professores e alunos passaram a ser produtores de informação, de textos... leitores.

Para muitos, foi a primeira experiência no uso das tecnologias e, em alguns casos, os alunos assumiram o papel de mediadores, para que seus professores pudessem se apropriar das ferramentas de comunicação e de interação e fazerem uso destas.

Ao longo do Curso foram criados 130 blogs, disponíveis no endereço: http://www6.ufrgs.br/mediadoresdeleitura/index.php?option=com_content\&view=articl e\&id=56\&Itemid $=56$

Dentre os nomes dos blogs, pode-se destacar: "Encantos da Leitura"; "Ler é uma viagem que só faz bem"; "Formando Leitores"; "Identidade Literária Rural"; "Leitores do Mundo", entre outros títulos que promovem e incentivam a leitura para os alunos, para a comunidade local e para todos os usuários da rede.

Pode-se destacar a importância deste Curso na formação de professores para a mediação da leitura e uso das TICs através dos depoimentos a seguir:

"Houve envolvimento emocional nesse curso de curta duração que, confesso, pensei que não seria possível na modalidade a distância, mas APRENDI que é possível, sim. Esse tipo de iniciativa deve acontecer com freqüência para motivar os educadores a refletirem sobre a prática e desafiá-los a se 'ver' como mediador de leitura". (LF)

A professora ainda destacou que o Curso refletiu em sua prática, pois a partir dele passou a trabalhar mais com intertextualidade, mesclando com imagens, poemas, notícias e crônicas mediadas pelas tecnologias.

No Seminário de Avaliação (presencial), MGS fez o seguinte comentário:

\footnotetext{
"Quero aproveitar este espaço para manifestar minha gratidão pela experiência vivida. Gostaria de dizer que não é nada fácil enfrentar obstáculos que tentam bloquear nossa chegada à autonomia. Ainda estamos muito presos a paradigmas que sustentam nossas crenças, porém agradeço muito por não ter deixado passar esta oportunidade pra crescer como pessoa e profissional e dizer que fiquei feliz e agradeço muito por ter recebido o auxílio de mediadores competentes e motivadores do nosso potencial. Pois a diversidade de idéias que se viu de apresentações dos colegas tanto nos blogs, quanto nos projetos foi fantástica" (MGS).
}

A professora ALG lembrou que tinha as melhores expectativas para o curso. E que com o encontro, sentiu o início de um trabalho de conscientização da importância da leitura não só na sala de aula, mas também em outros ambientes da vida social e a professora TR, disse que se sentiu desafiada e motivada a aceitar novas tarefas em sua vida profissional. "Este curso me fez ter a visão do quanto à formação é necessária para os nossos professores, foi uma explosão de experiências". "Estávamos a distância e o encontro presencial revelou o quanto éramos próximos", concluiu a professora.

A professora HO do Curso Mediadores de Leitura na Bibliodiversidade, destacou sobre a experiência do encontro presencial:

"Iniciamos por uma apresentação geral dos componentes do encontro e apresentação dos blogs. Nossas discentes estavam ansiosas e ao mesmo tempo felizes ao mostrar suas criações, postagens e escolhas. De tudo, uma coisa ficou certa: demos início à jornada e os blogs sobreviverão ao curso, já que entendidos como uma ferramenta pedagógica de auxílio à prática mediadora da leitura!” (HO).

Os blogs possibilitaram a criação de atividades para aplicação em sala de aula e foram elaboradas diversas práticas de leitura. Esta produção foi multiplicada, uma vez 
que cada pólo estava dividido em diversos grupos de alunos, cada grupo com seu blog, numa relação potencial intra-pólos e entre pólos, expandindo o material a ser postado e visitado, enriquecendo toda esta experiência, onde, claramente, a diversidade encontrava a unidade, refletida na qualidade do material produzido.

\section{Considerações Finais}

O uso do blog como uma ferramenta de informação e de comunicação, complementar ao AVA, possibilitou a todos envolvidos no Curso, atingir a comunidade em sua diversidade como mediadores de leitura - através do compartilhamento, da mediação e da interação, tornando-se uma experiência de promoção das práticas leitoras e de democratização dos saberes.

Através do uso das ferramentas, das TICs, os professores foram capazes de construir, de criar, não somente entre eles, mas com seus alunos, em consonância com o perfil do professor de "Era do Conhecimento" que ensina o aluno a aprender a aprender e aprende com este, perde o medo do computador, garante o acesso do aluno à informação, entre outros, e acima de tudo, é um mediador de leitura... um educador.

Em um processo de inclusão no cenário educacional e tecnológico pode-se dizer que foi possível concretizar a formação destes professores, respeitando e valorizando as suas diferenças e a diversidade. Verificou-se que o acesso e uso das ferramentas e o processo de interação entre os professores e destes com os outros, propiciou a inclusão em um AVA e a aprendizagem, na formação em serviço de professores da rede pública do Rio Grande do Sul, através da EAD mediada por computador.

\section{REFERÊNCIAS}

AMERICAN ASSOCIATION OF SCHOOL LIBRARIANS. O Aprendiz do Século XXI. Disponível em: <http://www.crb8.org.br/noticias_crb.php?codigo=272>. Acesso em: 01 maio 2012.

BRASIL. Lei No 9.394, de 20 de dezembro de 1996. Lei de Diretrizes e Bases da Educação Nacional. Disponível em: http://portal.mec.gov.br/seed/arquivos/pdf/tvescola/leis/lein9394.pdf. Acesso em: 10 ago. 2012.

LOPES, Rosana Pereira. Um Novo Professor: novas funções e novas metáforas. In: Redes Digitais e Metamorfose do Aprender. Petrópolis-RJ : Vozes, 2005. P.3355 .

MORO, E. L. da S.; ESTABEL, L. B. A Mediação da Leitura na Família, na Escola e na Biblioteca através das Tecnologias de Informação e de Comunicação e a Inclusão Social das Pessoas com Necessidades Especiais. Inclusão Social, Brasília-DF, v. 4, n. 2, p.67-81, jan./jun. 2011.

PEDROSA, Stella Maria Peixoto de Azevedo. A Educação a Distância na Formação Continuada do Professor. Educar em Revista, n. 21, p. 67-81, 2003.

RAMAL, Andrea Cecilia. Entre Mitos e Desafios. Pátio Revista Pedagógica, Porto Alegre, ArtMed, v.5, n.18, p.12-16, ago/out.2001.

REGO, T. C. Vygotsky: uma perspectiva histórico cultural na educação. Petrópolis: Vozes, 1995.

ULLRICH, W. Os Blogs como Ferramentas de Informação, Comunicação e Interação no Curso Mediadores de Leitura na Bibliodiversidade. In: Mediadores de Leitura na Bibliodiversidade. Porto Alegre: Evangraf/SEAD/UFRGS, 2012. 